\title{
NARRATIVAS SEM DIVISÕES DE PARÁGRAFOS EM BERNARDO CARVALHO, JOÃO GILBERTO NOLL E SAMUEL RAWET
}

Jaime Ginzburg

Universidade de São Paulo/CNPq

\section{RESUMO}

No conto "Ciúmes", de Bernardo Carvalho, o protagonista é um homem poderoso e autoritário, lidando com o crime organizado. Um importante aspecto desse texto é o fato de que não há divisão de parágrafos, como se a narrativa devesse ser exposta e compreendida em uma leitura ininterrupta, como um fluxo singular e contínuo. $\mathrm{O}$ artigo discute a importância desse recurso formal. $\mathrm{O}$ conto foi lido em comparação com outros textos, de autoria de Samuel Rawet e João Gilberto Noll.

PALAVRAS-CHAVE: Narrativa; parágrafos; Bernardo Carvalho; Samuel Rawet; João Gilberto Noll

O conto "Ciúmes", de Bernardo Carvalho, é constituído de uma forma ambígua. Do início ao final há uma única voz presente, caracterizando um monólogo. No entanto, ocorrem referências constantes a um interlocutor, como se o leitor estivesse diante de uma cena em que devesse ocorrer um hipotético diálogo. Essas referências incluem alusões a reações desse interlocutor ao que é dito, como, por exemplo, "Tá rindo do quê?" (CARVALHO, 2017, p.239).

O narrador-protagonista se apresenta como um secretário de segurança, e se dirige a um homem que está encarcerado em uma prisão de 
segurança máxima. A motivação principal para a conversa consiste em fazer com que o prisioneiro revele o paradeiro de seu advogado de defesa, e exponha uma mensagem cifrada que teria sido transmitida daquele para este. O secretário de segurança não conhece o teor nem a função dessa mensagem, e ignora para onde esse advogado teria ido.

O discurso do narrador é enunciado em um espaço claustrofóbico, dentro da prisão. Não há nenhuma cena desenvolvida fora desse enquadramento. A configuração da enunciação é constituída de modo linear, de maneira que, entre o início e o final do texto, a posição do narrador não é alterada, como se ele estivesse falando em um fluxo contínuo e ininterrupto. Tanto o espaço narrativo como o tempo da enunciação são delimitados de maneira a sugerir uma situação opressora para o prisioneiro. Reprimido em um espaço limitado e hostil, e exposto a uma fala longa e agressiva, o ouvinte não se manifesta. Isso tem como efeito a percepção, muito intensa e constante, de que o narrador é autoritário, e está empenhado em submeter o interlocutor aos seus interesses.

Cabe observar, por exemplo, o trecho inicial do conto:

Se estou contando, é porque você não vai sobreviver. Não sou louco de deixar uma testemunha viva. Quer dizer, quanto mais eu falar, mais vou me comprometer - e menores serão suas chances. Toda história é uma contagem regressiva. Você está entendendo, não é? Ninguém vai saber que estive aqui. Não fica bem. Não estou em posição de me comprometer. Eu podia parar agora mesmo. Bastava você abrir a boca, me interromper, dizer alguma coisa. Mas como, pelo jeito, você não vai me perguntar nada, também não vou ter que responder. Pode haver encontro mais ridículo que o nosso? Afinal, para que é que você me fez vir até aqui, se não foi pra revelar alguma coisa? Ou vai dizer que não me fez vir até aqui? Você pode não responder, mas nada me impede de continuar perguntando, correto? É claro que, a cada nova pergunta sem resposta, suas chances de sobreviver diminuem um pouco mais. (CARVALHO, 2017, p.226)

Nesse trecho, a palavra "você" aparece seis vezes, e o pronome "me", cinco vezes. A essa reiteração constante são somadas duas ocorrências de "eu", e também duas do pronome "suas". No espaço de poucas linhas, essas reiterações são importantes. Com elas, a narrativa marca com muita evidência a presença do personagem que fala e daquele que o escuta. A ênfase na segunda pessoa do discurso delimita o horizonte da enunciação. A ameaça de morte, indicada na primeira linha, expressa um comportamento fascista: a desobediência do outro, entendida como desa- 
cato à autoridade política do falante, será punida com a aniquilação. No entanto, a necessidade de obter uma resposta cria desdobramentos dessa ameaça, como se fosse necessário oferecer uma alternativa ao inquirido. As chances de sobreviver variam de grau - podem ficar menores, podem diminuir - mas, ao contrário do que sugere explicitamente a primeira frase, elas não estão esgotadas, e dependem, em hipótese, da colaboração do ouvinte no interrogatório.

A palavra "não" aparece dez vezes, nesse fragmento inicial. Essa reiteração permite observar a importância, para o narrador, de percepções negativas sobre o que ocorre e o que pode ocorrer. Ao longo do texto, o efeito da repetição desse termo, ao lado de outros, como "ninguém" e "nada", entre outros, permite perceber uma linha reiterada de pensamento, que consiste em dar atenção a antagonismos e situações conflitantes. Essa linha é muito importante para a caracterização do protagonista. Outro aspecto fundamental é a presença de frases interrogativas. No mesmo fragmento, são cinco casos. Cada pergunta contribui para a tensão da cena, e confere visibilidade à incerteza com que o secretário de segurança lida com a situação. É como se, por um lado, o fato de ser a única voz com fala no conto indicasse um poder discursivo, um controle sobre o ouvinte, e por outro, as interrogações sugerissem dificuldades de lidar com a expectativa de solucionar as dúvidas. Por exemplo, a frase "Eu podia parar agora mesmo" sugere um controle da situação por parte do secretário; em "Pode haver encontro mais ridículo que o nosso?", contrariamente, o narrador observa o que faz de maneira crítica, como se estivesse iludindo a si mesmo.

As questões levantadas pelo narrador são numerosas, e não apenas em razão de que ele quer extrair uma confissão do prisioneiro. O secretário de segurança aborda seu interlocutor como um "gênio do crime"; explicitamente, ele descreve a cena em que está inserido como "O secretário de Segurança apelando ao gênio do crime” (CARVALHO, 2017, p. 236). Essa elevação ambígua do interlocutor a um estatuto diferenciado está ligada à presença, no conto, de referências intelectuais. $\mathrm{O}$ prisioneiro teria falado sobre Kierkegaard com seu advogado, e recitado Dante em um vídeo gravado para a internet (CARVALHO, 2017, p. 228). O narrador sugere que o interesse por esses autores teria sido um fator de aproximação entre o advogado e o inquirido. Pelo menos em parte, a persistência do interrogatório, mesmo diante do silêncio por parte do prisioneiro, é motivada pela atribuição dessa genialidade, como se fosse imprescindível 
considerar, com atribuição de valor de verdade, aquilo que o interrogado confessasse.

Causa estranheza, dentro desse conjunto de elementos, a elaboração difusa de alusões ao amor. A cada vez que irrompe, nas poucas vezes em que surge, a palavra "amor" destoa de substantivos apresentados em linhas anteriores, como se necessariamente devesse provocar uma inquietação. No seguinte trecho, essa irrupção aparece:

É isso que você quer provar? Que basta o poder pra levar um homem como ele a se rebaixar à pior escória da humanidade? E que basta $\mathrm{o}$ poder pra transformar um advogado brilhante em menino de recados? Foi pra isso que você me fez vir até aqui? Pois eu vou te dar meu ponto de vista. Você sabe o que leva um homem como ele a fazer isso? O que leva um advogado como ele a fazer isso é o que você não previu quando confiou nele como advogado. É o amor. E o amor é volúvel. Ou não é? Você achou que era amor pelo que você representa? (CARVALHO, 2017, p.232)

As palavras "poder", "escória" e "advogado" estão diretamente associadas à trama referente à busca do teor da mensagem secreta. Esse vocabulário é coeso com relação a afirmações anteriores por parte do narrador, e também ao perfil político que o caracteriza, como secretário de segurança. Não é o mesmo caso com a palavra "amor". O movimento discursivo é dissociativo, de um horizonte institucional para a intimidade, de uma posição de um representante do poder público para uma expressão de um sentimento. Em termos sintáticos, o trecho se assemelha muito ao fragmento anteriormente transcrito. Em poucas linhas, ocorrem sete perguntas. Outra forte semelhança está no vocabulário: assim como no caso anterior, a palavra "você" aparece com frequência no espaço do fragmento - cinco vezes, em poucas linhas.

As semelhanças entre os dois trechos transcritos, em termos da pontuação, com a presença das interrogações, e de vocabulário, particularmente no que diz respeito ao termo "você", mostram uma continuidade estilística entre as duas passagens. O que surpreende é a presença de um campo semântico que emerge inesperadamente. As primeiras páginas sugerem que os conflitos principais diziam respeito à função pública do secretário. Quando ele começa a falar em amor, muda significativamente a delimitação de alcance dos conflitos entre os dois personagens. É como se as decisões do advogado tivessem sido motivadas por fatores independentes da política. 
Em termos contextuais, de acordo com o narrador, a situação é muito perigosa: as ações do advogado podem levar a "espalhar o pânico (...) paralisar a cidade (...) uma nova guerra do crime (...) uma onda de sequestros e chacinas" (CARVALHO, 2017, p. 229). Diante disso, ele estaria sob pressão de "mídia, partido político, opinião pública" (CARVALHO, 2017, p. 237). No momento presente da enunciação, a incerteza o preocupa, pois já teria corrido tempo suficiente, desde o momento em que o advogado desapareceu, para que problemas tivessem ocorrido, mas até ali "não houve nada, nenhum pânico, nenhuma chacina, nenhuma onda de sequestro, nenhuma retaliação violenta contra o bloqueio do sinal de celular no presídio de segurança máxima" (CARVALHO, 2017, p. 238).

O conto pode ser lido, de acordo com termos de Shoshana Felman, como um conjunto de jogos de linguagem, em que lacunas de compreensão podem levar a provocar estranhamento, em razão de uma diferença entre o que é dito pelo secretário e a maneira como é dito. A afirmação de um poder, por parte do secretário, que permite com que faça ameaças ao prisioneiro, anuncie que vai matá-lo, e permaneça interrogando sem a presença de um advogado, expressa uma grande força de autoridade. Esse posicionamento não se sustenta nas condições concretas de enunciação, em que as incertezas são numerosas. Isso consiste, seguindo os argumentos de Feldman (FELDMAN, 2003, p. 251-252), em um paradoxo, em que retoricamente a imagem de racionalidade imposta pelo discurso contraria a dinâmica ansiosa e fragmentada de sua enunciação.

A elevada frequência de frases interrogativas, a insistência no apelo à segunda pessoa do discurso e a reiteração de termos negativos, entre outros recursos, contribuem para a tensão da cena de interrogatório. Embora a ênfase esteja em uma ação que aparenta ser justificada institucionalmente (trata-se de um secretário de segurança supostamente interessado em evitar a irrupção de violência e de ações do crime organizado na cidade), aos poucos, ao longo do conto, vai ganhando importância uma trama diferente.

O narrador, de acordo com essa trama, estabelece que existe um relacionamento, caracterizado como amoroso, entre ele próprio e o advogado desaparecido. Além disso, sugere que o interlocutor tem um envolvimento com o mesmo homem. De modo difuso e incompleto, aparecem rastros de um triângulo amoroso. Como se estivesse inicialmente reprimido e aos poucos emergisse no discurso, o interesse homoafetivo por parte do secretário ganha visibilidade. 
Ainda no início do conto, é feita uma menção breve a aproximações homossexuais na adolescência. Em contraste, o narrador, após trazê-las à tona, afirma: "Coisas de garoto. Pode contar. Meu negócio, por exemplo, é mulher. Sou um homem casado e com filho. E não estou aqui pra me comprometer." (CARVALHO, 2017, p.227). A sugestão breve de homossexualidade estaria sendo, para o narrador, contradita por sua situação conjugal, como se ele precisasse provar ao interlocutor sua virilidade. O verbo "comprometer" se refere, nessa linha discursiva, ao risco de que sua imagem masculina e heterossexual fosse contrariada.

Em outros momentos, o secretário de segurança faz afirmações que, em hipótese, cumprem a função de demonstrar ao prisioneiro um grande interesse por parte do advogado. Por exemplo, em sua fala, ele evoca tempos em que estudava na faculdade, tendo o desaparecido como colega, com o qual tinha constantes confrontos por diferenças de pensamento. Na opinião do narrador, a relação com o advogado foi constituída com um constante despertar de interesse; em perspectiva narcísica, o secretário acredita que decisões tomadas pelo homem que amava resultaram de uma vontade de antagonizar.

O protagonista questiona o prisioneiro a respeito das condutas do advogado, ponderando sobre os interesses que as motivam. Em um momento, destaca que o desaparecido nunca perdia nenhuma causa, mas especificamente fracassou na tentativa de evitar a transferência do inquirido para uma prisão de segurança máxima. A singularidade desse fracasso é compreendida pelo secretário como um ato performativo. Essa performance consistiria em que "ele faz tudo contra o que eu faço e contra o que eu penso" (CARVALHO, 2017, p.237); isto é, as ações do advogado expressariam uma contínua e obsessiva necessidade de antagonizar com o secretário, dando continuidade aos confrontos da faculdade. Este se considera o espectador para quem o advogado apresenta suas ações. Como se as vidas dos outros se restringissem ao espaço de sua própria consciência, o narrador propõe a si mesmo como ponto de convergência das motivações para as decisões tomadas pelo advogado. Com base nessa premissa, afirma que ele assumiu a defesa do prisioneiro com o único fim de "despertar meu ciúme. Porque eu sou tudo o que importa para ele" (CARVALHO, 2017, p.237-8).

$\mathrm{O}$ conto não apresenta elementos textuais suficientes para definir com precisão exata se o advogado mantém ou manteve regularmente envolvimentos homossexuais ou homoafetivos com o secretário e, simulta- 
neamente ou não, com o prisioneiro. Como narrador em primeira pessoa, ele pode falar sobre fantasias, sem que o leitor tenha elementos seguros para ter certeza quanto às diferenças entre produtos de sua imaginação e eventuais experiências concretas, dentro dos limites do texto. Por essa razão, não é viável ter certeza quanto às motivações do advogado para tomar decisões, como atuar como defensor do prisioneiro, receber a mensagem secreta, ou desaparecer, entre outras. Embora a perspectiva política de desenvolvimento do enredo seja detalhada, com observações específicas sobre a ameaça representada pelos interesses do interrogado, prevalece no final a perspectiva intimista, segundo a qual os acontecimentos são governados por uma disputa entre o narrador e o prisioneiro. Esse conflito, inicialmente percebido como um problema entre um representante do Estado e um criminoso com poder de liderança, com implicações para a cidade como um todo, toma ao final a forma de um impasse entre dois homens interessados em um mesmo terceiro. No final, de maneira fragmentária, o narrador expõe que o advogado teria sido incentivado pelo prisioneiro a entregar a suposta mensagem secreta no espaço de uma facção inimiga do crime organizado. De acordo com o narrador, a entrada nesse espaço significaria uma exposição à morte. Mesmo de modo incompleto e incerto, a parte final do conto sugere que o prisioneiro teria planejado a morte dele, em razão de ciúmes. Nesse caso, o interrogado teria reconhecido que existia uma ligação entre o secretário e o advogado e, descontente, teria decidido eliminar o homem que o defendia. A atitude passional prevaleceria, desse modo, sobre a intriga política; isso justificaria a escolha do título do conto.

Bernardo Carvalho escolheu uma configuração formal específica para esse conto. Entre seu início e seu final, não existe nenhuma divisão de parágrafos. A aparência é de um bloco discursivo. Embora heterogêneo em termos de construções frasais e de vocabulário escolhido, a narração do secretário é exposta em um único e longo jorro. Para o leitor, o efeito é de que não é possível tomar fôlego.

Divisões de parágrafos podem sinalizar mudança de assunto, deslocamento no espaço, passagem do tempo, ou mesmo mudança de ênfase, entre outras possibilidades. Em textos argumentativos convencionais, a construção de parágrafos é regulada em acordo com critérios próprios a esse tipo de discurso, como a gradação de complexidade do conhecimento e a coesão textual (FISHMAN, 1978, p.160). Em suma, em contextos não literários de uso, divisões de parágrafos atuam como fatores de ordenação 
de percepções. A escolha, em um texto literário, pela ausência de quaisquer divisões de parágrafos pode consistir em uma transgressão a padrões convencionais ou habituais de percepção e de elaboração de ideias. Uma transgressão como essa pode ser expressa, por exemplo, pela configuração do tempo narrativo.

No caso de "Ciúmes", a configuração textual acentua a continuidade da fala do secretário de segurança, como se ocorresse de modo ininterrupto ao longo da duração da enunciação; ou ainda, como se o tempo da leitura correspondesse em exatidão ao tempo da enunciação.

Como o discurso é autoritário, e a cena é de um interrogatório repressivo, a ausência de divisão de parágrafos acentua o impacto do autoritarismo. Como um único bloco discursivo ininterrupto, a fala do secretário de segurança, ainda que em certos pontos sinalize eventuais reações do interlocutor, é caracterizada predominantemente por ser autocentrada. Sendo uma narração em primeira pessoa, os acontecimentos só são acessíveis ao leitor por meio da percepção específica do secretário, sem que outros pontos de vista estabeleçam perspectivas diferentes sobre as ocorrências. Com isso, além de um cenário claustrofóbico, uma fala autoritária e uma situação intimidadora, o texto apresenta uma fala em fluxo, deixando a impressão de que foi conduzida sob ansiedade, e sem pausas. $\mathrm{O}$ interesse do protagonista por controlar a situação, extraindo respostas do inquirido, é coerente com esse andamento da narração; nos dois casos, a impressão geral é de falta de moderação.

As variações de pontuação e de ritmo provocam transformações em termos de intensidade do impacto do discurso. O impacto das frases interrogativas, por exemplo, é importante para eliminar a impressão, despertada na primeira frase do conto, de que o secretário teria invariavelmente um poder de vida e morte sobre os outros. A elevada frequência de referências em segunda pessoa do discurso permite observar que $o$ seu poder político encontra limites diante do inquirido. Por essas razões, entre outras, o discurso do narrador, à medida em que avança, tem sua opacidade mais consolidada.

Cabe enfatizar o efeito físico da opção em manter a narração em um fluxo ininterrupto. Na prática, uma mudança de parágrafo pode representar uma oportunidade para que o leitor, se quiser, tome fôlego, inclusive fisicamente. $\mathrm{O}$ final de um parágrafo pode ser uma deixa para que um leitor feche temporariamente seu livro, se distraia, e volte ao texto com a convicção de que, reiniciando sua leitura em um novo parágrafo, 
encontrará um ponto em que algo de novo será exposto. O conto de Carvalho parece particularmente destinado a leitores tão ansiosos quanto o narrador, que não desloquem o olhar para fora da página, e que se mantenham focados continuamente. Para leitores que não estão habituados a essa agilidade, o texto pode ser exaustivo. Figurativamente, é possível que os leitores estejam expostos a um desgaste físico que aponte, ainda que remotamente, para formas de mal-estar vivenciadas por um prisioneiro em uma instituição de segurança máxima. Para esse efeito, a repetição constante do termo "você" cumpre um papel de mediação, sugerindo, indiretamente, que pode ser que o próprio leitor se sinta identificado com a posição do prisioneiro, exposto a uma fala longa e hostil não solicitada.

A unidade textual, delimitada no espaço das páginas, entre o início e o final, sugere que se trata de uma estrutura totalizante, em que todas as partes estão integradas por um ponto de vista rígido, em um único fluxo discursivo. Essa impressão, no entanto, é superficial; internamente, elementos dissociativos eliminam a ilusão de totalidade de sentido. Embora o conto pareça convidar para uma leitura em bloco e em um único fôlego, a materialidade do texto aponta para incertezas agônicas, que estão relacionadas com o passado e o presente. Em acordo com Christian Godin, é possível afirmar que, artisticamente, a totalidade de "Ciúmes" é elaborada como um movimento em torno do "indizível" e do "inefável", em que cesuras e elipses são importantes (GODIN, 1997, p.260). Isso significa que, sendo lido como um bloco discursivo único sem divisões de parágrafos, o conto dá visibilidade ao que nele não é completo ou suficientemente explicado.

Em outros textos literários brasileiros, a estratégia de não apresentar divisões de parágrafos pode cumprir funções diferentes. Um caso importante é o romance Acenos e afagos, de João Gilberto Noll. Em aproximadamente duzentas páginas, acompanhamos a trajetória de um protagonista que, inicialmente, leva uma vida de pai de família, faz sexo com a esposa e dedica atenção ao filho. A partir de um certo ponto, motivado por lembranças e fantasias, passa a ter interesses por homens. Em especial, por um amigo de infância, a quem se refere como o engenheiro.

O protagonista é agredido, em meio ao seu percurso de aproximação de homens, por um rapaz jovem, e morre. É enterrado, comenta conscientemente seu enterro, e pouco depois aparece em um carro com o engenheiro. Este conta que o retirou da cova, e que o leva para, longe dali, viverem juntos. O romance não apresenta explicações sobre isso, como, em hipótese, indicar que na verdade ele não teria morrido ou, investindo 
em uma abordagem sobrenatural, definir que se tratava de um fantasma. Além de não propor justificações, o narrador segue com sua vida nova, sem perplexidade ou choque com relação ao que ocorreu.

Mais adiante, vivendo com o engenheiro, aos poucos reconhece que deseja viver como mulher. E com o passar do tempo, se transforma em acordo com seu desejo. Nesse caso também não há explicações por parte do narrador: não ocorre operação cirúrgica de mudança de sexo, e não há uma definição de que se trate de um travesti, ou de um homem que se comporta em imitando mulheres. Sem nenhuma definição, o protagonista passa a ver seu corpo e seus afetos como sendo de uma mulher. É relevante para compreender essas transformações, por exemplo, o seguinte trecho:

Em certos instantes me mostrava tão feminina agora, que me apaixonava, sim, pelo homem que eu fui. Em mim coabitavam os dois amantes. No entanto não alimentava anseios mórbidos por épocas finadas. Ao contrário, me agarrava ao amor daquele homem que tinha me dado uma outra vida, a melhor talvez, aquela que produzia em mim um oceano de vozes para um só coração (NOLL, 2008, p.106-107).

A coabitação de homem e mulher não leva a exigir, para o narrador, a atribuição de um nome, ou de uma categoria científica para sua nova forma de vida. Nesse ponto, é possível se referir à protagonista ou ao protagonista, sendo que nenhuma dessas duas formas é propriamente exata. O livro de Noll alcança um ponto em que a linguagem cotidiana não tem recursos para traduzir com precisão aquilo que é vivido.

Essa situação limite é beneficiada, em termos de expressão literária, pela ausência de divisões de parágrafos no romance. É como se João Gilberto Noll tivesse atravessado a necessidade de uma ruptura epistemológica. Para caracterizar um mundo em que as distinções entre vivo e morto e entre mulher e homem estão suspensas ou ultrapassadas, é esteticamente necessária uma concepção discursiva que suprima distinções constantemente adotadas em usos sociais de linguagem. A distinção entre um parágrafo e outro, tanto na distribuição do espaço da página, como no que se refere à especificidade expressiva de cada um, é uma das mais primárias para a escrita de narrativas. Forma e tema se articulam, de modo a permitir que a situação limite seja expressa com a necessária força.

Ao contrário do que ocorre em "Ciúmes", não há nenhum traço autoritário no discurso. Também não há um interlocutor estabelecido para o conjunto da narração. As cenas ocorrem em vários momentos de tempo 
e variados espaços, diferentemente da concentração da cena no texto de Bernardo Carvalho. Embora a concepção formal empregue um mesmo recurso, as funções desse emprego se distinguem. Em Acenos e afagos, a ausência de divisão de parágrafos contribui para aumentar a coesão dos episódios narrados, evitando que eles pareçam independentes. Isso é importante principalmente por não estabelecer cortes precisos entre o período de tempo em que a(o) protagonista se percebia como homem, e o tempo em que se percebeu como mulher; similarmente, por não distinguir de modo preciso o período em que vivia antes do enterro, e a continuidade de sua vida após esse enterro até o final. Nesse romance, nos termos de Gerd Bornheim, "o corpo se impõe como o único meio que legitima o fato de que podemos atingir os fenômenos sensíveis; pelo corpo eu me faço mundo e transformo o percebido em carne" (BORNHEIM, 2001, p.141). Nos dois processos ocorrem transições cujas fronteiras temporais não são nítidas. É justamente a abertura para as transformações que se beneficia da sintaxe da narrativa: em um romance cuja (o) protagonista rompe com categorias binárias de caracterização da vida humana, a ausência de divisões de parágrafos permite ao leitor acompanhar processos e transformações como um fluxo vivido sem subordinação a modelos fixados. Em "Ciúmes", o emprego desse mesmo recurso formal resulta em tensão. O protagonista concentra seu discurso e sua atenção em um espaço e um tempo narrativo muito circunscritos. O texto apresenta elementos claustrofóbicos e expressa intensa repressão por parte do narrador sobre seu interlocutor.

Antes da publicação desses textos de Bernardo Carvalho e João Gilberto Noll, Samuel Rawet construiu narrativas utilizando o mesmo recurso. Em seu livro Que os mortos enterrem seus mortos, de 1981, diversos contos são configurados sem divisão de parágrafos. "O riso do rato", por exemplo, é um texto referente ao final da Segunda Guerra Mundial e ao governo de Getúlio Vargas. É um relato de uma experiência negativa que deixou rastros de sangue (ADORNO, 2011, p.42-43). O narrador, em terceira pessoa, apresenta um protagonista que está decidido a matar um homem. Entre tensões no espaço público, com imagens de tanques nas ruas no contexto em que "Derrubaram Getúlio" (RAWET, 2004, p.348), e problemas envolvendo uma mãe presa e um filho doente, o conto expõe as tensões que levam o protagonista a ponderar, e mudar de ideia quanto ao assassinato. Algumas semelhanças entre "O riso do rato" e "Ciúmes" podem ser notadas, como: o fato de que, nos dois casos, a primeira linha 
de cada texto determina uma expectativa de matar; em ambos existe uma relação direta entre violência no espaço público e problemas relativos à intimidade; nos dois, existem referências à busca por esclarecer algo que não está bem compreendido.

O conto "Moira", no mesmo livro de Rawet, se assemelha com "Ciúmes", particularmente, pela concentração de uma grande incidência de questionamentos por parte do narrador. Muitas frases com pontos de interrogação se sucedem, concentradas em espaços de poucas linhas. Além disso, algumas imagens contribuem para caracterizar a situação como agônica: "O tempo. O fluxo do tempo. Um instante. Fração de quê? Entre passado e futuro o presente estrangulado, compacto, quase ausente" (RAWET, 2004, p.358). De modo indireto, essa passagem remete ao espaço repressivo e claustrofóbico no texto de Bernardo Carvalho.

Cabe dar atenção a dois textos, em particular, dentro do mesmo volume de Rawet: "As palavras" e "Nem mesmo um anjo é entrevisto no terror". O narrador de "As palavras" apresenta um personagem com cinquenta anos de idade, casado, com dois filhos adultos. Em sua vida, estão “Os pais. Os sogro. Os amigos. O amante." (RAWET, 2004, p.376). O relato expõe esse personagem nu, na intimidade, contemplando o corpo do amante, que dorme.

O olhar se move no ambiente, e a contemplação propicia uma enumeração fragmentária e heterogênea - "O armário. Os discos. As revistas. A vitrola. Copo. Garrafa. Os olhos varrem os objetos. Corpo-objeto. Corpo-corpo." (RAWET, 2004, p.377). Cada fragmento pode ser lido como um traço ou um resto de hipotéticas estórias importantes e complexas que não foram enunciadas. A observação de fragmentos, nesse conto, expressa uma inquietação, tanto com o presente, como com a memória. Em acordo com Erich Auerbach, aqui está em jogo "a confiança de que em qualquer fragmento escolhido ao acaso, em qualquer instante, no curso da vida está contida e pode ser representada a substância toda do destino" (AUERBACH, 1976, p.493). A narração acentua a dificuldade, por parte do personagem, de se tranquilizar diante do corpo do amante. Logo depois, uma cena dentro de um cinema estimula interrogações. Ao final, o personagem caminha, e sua contemplação da Rua do Catete motiva uma epifania intransitiva: "Há." (RAWET, 2004, p.377). O efeito de leitura consiste em propor uma subversão do título. Ao longo do texto, as palavras - muitas vezes, expostas como fragmentos, talvez como traços de uma estória não contada - não são suficientes para atribuir sentido ao que está sendo vivido. 
Um ambiente noturno serve de contexto para as ações de "Nem mesmo um anjo é entrevisto no terror". Assim como "As palavras", esse texto apresenta elementos visuais de modo dissociativo, sugerindo movimentos de um olhar por cenas associadas a práticas homossexuais. Em um local, aparece uma lembrança, por parte de um personagem, de noites do passado, em que era esperado "que toda a fome afetiva se realizasse num contato sôfrego de dedos ou lábios, no intervalo de uma presença e outra presença" (RAWET, 2004, p.367). O conto se volta para o universo da prostituição masculina. Mais uma vez há uma referência a um homem "casado, tinha mulher, e filhos" (RAWET, 2004, p.368), que procura na madrugada contato homossexual.

Considerando as especificidades dos seis textos literários mencionados neste trabalho, é possível estabelecer relações de semelhança e diferença entre eles. Em especial, a aproximação de "As palavras" e "Nem um anjo é entrevisto no terror" com "Ciúmes" permite observar afinidades temáticas. Nos três textos, está presente um homem que, sendo casado com filho(s), vivendo de modo socialmente aceito, expõe desejo por outro homem. Nos três casos, esse desejo é exposto de modo associado a uma tensão ou um incômodo. No entanto, nenhum dos contos mencionados de Samuel Rawet apresenta um narrador autoritário. Em nenhum deles, existe uma construção focada no interlocutor. Prevalece nesses textos de Rawet uma linha meditativa de narração, caracterizada por um apelo a recursos visuais. O movimento do olhar é muito importante no livro Que os mortos enterrem seus mortos. Cabe registrar, no que se refere especificamente à presença de um homem casado com filho, que isso ocorre também em Acenos e afagos.

Os quatro contos de Samuel Rawet são caracterizados, cada um a seu modo, por singularidades. A incerteza diante do fim do Estado Novo em "O riso do rato" e a inquietação sobre a passagem do tempo em "Moira" são elementos que remetem a descompassos entre uma individualidade e o andamento das coisas à sua volta. Nesses dois casos, antecipando parcialmente a forma de Acenos e afagos, a inteligibilidade dos personagens é favorecida pela composição sintática da prosa. A estranheza do leitor com relação à ausência de divisões de parágrafos contribui para acentuar o que há de inquietante nas situações narradas.

Acenos e afagos, "Ciúmes", "As palavras" e "Nem um anjo é entrevisto no terror" têm em comum a presença de referências à homossexualidade ou à homoafetividade. Nos quatro, aparecem expressões de 
desejo de um homem por outro. Embora não seja viável estabelecer generalizações, diante de um conjunto restrito de obras, é pertinente questionar a relevância desse fato. Uma pesquisa com maior tempo de duração poderia eventualmente refletir sobre a hipótese de que alguns escritores brasileiros contemporâneos, ao trabalharem com imagens da homossexualidade, procurem configurações formais que rompam com convenções de gêneros textuais conhecidos. Com isso, pelo menos em algumas obras, a especificidade dos desejos homossexuais com relação a práticas sociais dominantes poderia demandar rupturas com modos convencionais de recepção de textos literários. Escrever sem abrir novos parágrafos (em especial, no caso de uma narrativa longa) é um recurso eficaz para captar a atenção, pelo estranhamento que pode causar. Essa hipótese, no entanto, de imediato, não corresponde a uma definição conclusiva, permanecendo até o momento como dúvida.

O fato de que os seis textos mencionados são caracterizados pela ausência de divisões internas de parágrafos é relevante. É importante observar que esse recurso formal não traz em si uma significação invariável. A comparação entre Acenos e afagos e "Ciúmes" evidencia uma diferenciação. Quanto ao conto de Carvalho, a leitura em bloco acentua o mal-estar propiciado pelo autoritarismo do narrador, pelo impacto do interrogatório e pela situação claustrofóbica em que a fala é enunciada. No romance, a ausência de divisões de parágrafos não é, em si, um componente positivo nem negativo, mas um recurso estético capaz de estabelecer, para o leitor, um corpo textual tão singular quanto a (o) personagem central. No conto, pelo excesso de concentração de elementos em um tempo e um espaço restritos, essa ausência contribui para choques estéticos, instabilizando os horizontes de expectativa dos leitores. No caso do romance de Noll, a composição em bloco único se associa à singularidade $\mathrm{da}(\mathrm{o})$ protagonista, cujos processos de transformação não são redutíveis a categorias binárias ou a modos convencionais de representação. É como se um(a) personagem que nada tem de trivial demandasse, por necessidade estética da obra, uma forma que não fosse reconhecida pelos leitores como trivial. O corpo delimita e expande, em suas transformações, as condições linguísticas de sua própria expressão. 


\section{NARRATIVES WITHOUT PARAGRAPH BREAKS BY BERNARDO CARVALHO, JOÃO GILBERTO NOLL AND SAMUEL RAWET}

ABSTRACT

In "Ciúmes", a short story written by Bernardo Carvalho, the main character is a powerful and authoritarian man who's dealing with organized crime. One importante aspect in the short story is that there are not paragraph breaks, as if the narrative should be exposed and understood at once, without interruption, as a singular and continuous flow. In order to understand that, we discuss this formal resource and compare "Ciúmes" to other texts written by Samuel Rawet and João Gilberto Noll.

KEYWORDS: Narrative; paragraphs; Bernardo Carvalho; Samuel Rawet; João Gilberto Noll

\section{REFERÊNCIAS}

ADORNO, Theodor. Schonberg y el progresso. In: Filosofía de la nueva música. Madrid: Akal, 2011.

AUERBACH, Erich. Mimesis. São Paulo: Perspectiva, 1976.

BORNHEIM, Gerd. Sobre a linguagem musical. In: Metafísica e finitude. São Paulo: Perspectiva, 2001.

CARVAlHO, Bernardo. Ciúmes. In: GALERA, Daniel, org. Acerto de contas. Treze histórias de crime \& Nova literatura latino-americana. São Paulo: Companhia das Letras, 2017.

FELMAN, Soshana. Writing and madness (Literature/Phylosophy/Psychoanalysis). Palo Alto: Stanford University Press, 2003.

FISHMAN, Anne Stevens. The effect of anaphoric references and noun phrase organizers on paragraph comprhension. Journal of Literacy Research. V.10. N.2, 1978. 
GODIN, Christian. La totalité. Seyssel: Champ Vallon, 1997. V.4.

NOLL, João Gilberto. Acenos e afagos. Rio de Janeiro: Record, 2008.

RAWET, Samuel. As palavras. In: . Contos e novelas reunidos. Rio de Janeiro: Civilização Brasileira, 2004.

RAWET, Samuel. Moira. In: Contos e novelas reunidos. Rio de Janeiro: Civilização Brasileira, 2004.

RAWET, Samuel. Nem mesmo um anjo é entrevisto no terror. In: Contos e novelas reunidos. Rio de Janeiro: Civilização Brasileira, 2004.

RAWET, Samuel. O riso do rato. In: . Contos e novelas reunidos. Rio de Janeiro: Civilização Brasileira, 2004.

Recebido:30/01/2018

Aceito: 07/06/2018 